Signal Processing of Speech 
Macmillan New Electronics Series

Series Editor: Paul A. Lynn

Rodney F.W. Coates, Underwater Acoustic Systems

W. Forsythe and R.M. Goodall, Digital Control

C.G. Guy, Data Communications for Engineers

Paul A. Lynn, Digital Signals, Processors and Noise

Paul A. Lynn, Radar Systems

A.F. Murray and H.M. Reekie, Integrated Circuit Design

F.J. Owens, Signal Processing of Speech

Dennis N. Pim, Television and Teletext

M.J.N. Sibley, Optical Communications

Martin S. Smith, Introduction to Antennas

P.M. Taylor, Robotic Control

G.S. Virk, Digital Computer Control Systems

Allan Waters, Active Filter Design

\section{Series Standing Order}

If you would like to receive further titles in this series as they are published, you can make use of our standing order facility. To place a standing order please contact your bookseller or, in case of difficulty, write to us at the address below with your name and address and the name of the series. Please state with which title you wish to begin your standing order. (If you live outside the United Kingdom we may not have the rights for your area, in which case we will forward your order to the publisher concerned.)

Customer Services Department, Macmillan Distribution Ltd Houndmills, Basingstoke, Hampshire, RG21 2XS, England. 


\title{
Signal Processing of Speech
}

\author{
F.J. Owens \\ BSc, PhD, CEng, MIEE \\ Senior Lecturer \\ Department of Electrical and Electronic Engineering \\ University of Ulster \\ Jordanstown, Northern Ireland
}

Macmillan New Electronics

Introductions to Advanced Topics

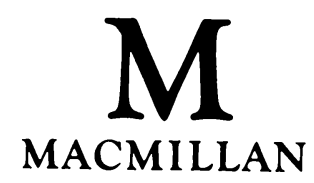


All rights reserved. No reproduction, copy or transmission of this publication may be made without written permission.

No paragraph of this publication may be reproduced, copied or transmitted save with written permission or in accordance with the provisions of the Copyright, Designs and Patents Act 1988, or under the terms of any licence permitting limited copying issued by the Copyright Licensing Agency, 90 Tottenham Court Road, London W1P 9HE.

Any person who does any unauthorised act in relation to this publication may be liable to criminal prosecution and civil claims for damages.

First published 1993 by

THE MACMILLAN PRESS LTD

Houndmills, Basingstoke, Hampshire RG21 2XS

and London

Companies and representatives

throughout the world

ISBN 978-0-333-51922-6

ISBN 978-1-349-22599-6 (eBook)

DOI 10.1007/978-1-349-22599-6

A catalogue record for this book is available from the British Library 
To

Mary,

Niall, Gareth, Niamh and Darren 


\section{Contents}

Series Editor's Foreword $\quad$ x

Preface $\quad$ xi

1 The Nature of Speech 1

1.1 Introduction 1

1.2 Mechanism of speech production 3

1.3 Source-filter model of speech production 5

1.4 Speech sounds 7

1.5 Co-articulation and prosody 9

1.6 Time waveforms and frequency spectra 11

1.7 The human auditory system 13

2 Digital Speech 17

2.1 Sampling 18

2.2 Pre-sampling filter 21

2.3 Quantisation $\quad 22$

2.3.1 Uniform quantisation 23

2.3.2 Logarithmic quantisation $\quad 25$

2.4 Adaptive quantisation 28

2.5 Differential quantisation (DPCM) 29

2.6 Adaptive differential quantisation (ADPCM) 30

2.7 Delta modulation 31

Problems $\quad 34$

3 Parametric Speech Analysis 35

3.1 Pre-emphasis 36

3.2 Filter banks for short-time spectral analysis 37

3.3 Discrete Fourier transform (DFT) 44

3.4 Fast Fourier transform (FFT) 50

3.5 Cepstral analysis of speech 53

3.6 The autocorrelation function 58

$\begin{array}{ll}3.7 \text { Linear predictive analysis (LPA) } & 59\end{array}$

3.8 Pitch-synchronous analysis 67

Problems $\quad 68$ 
4 Feature Extraction $\quad \mathbf{7 0}$

$\begin{array}{ll}\text { 4.1 Short-time energy function } & 70\end{array}$

$\begin{array}{ll}4.2 \text { Zero-crossing rate } & 71\end{array}$

$\begin{array}{ll}4.3 \text { Endpoint detection } & 72\end{array}$

$\begin{array}{ll}4.4 \text { Vector quantisation } & 72\end{array}$

$\begin{array}{ll}4.5 \text { Formant tracking } & 74\end{array}$

$\begin{array}{ll}4.6 \text { Pitch extraction } & 78\end{array}$

4.6.1 Gold-Rabiner pitch extractor $\quad 79$

$\begin{array}{ll}\text { 4.6.2 Autocorrelation methods } & 81\end{array}$

4.6.3 The SIFT algorithm $\quad 84$

4.6.4 Post-processing of pitch contours $\quad 85$

$\begin{array}{ll}4.7 \text { Phonetic analysis } & 85\end{array}$

5 Speech Synthesis $\quad 88$

5.1 History of speech synthesis $\quad 88$

5.2 Formant synthesisers $\quad 92$

$\begin{array}{ll}5.3 \text { Linear predictive synthesisers } & 100\end{array}$

$\begin{array}{ll}5.4 \text { Copy synthesis } & 101\end{array}$

5.5 Phoneme synthesis 102

5.6 Concatenation of multi-phonemic units 107

$\begin{array}{ll}5.7 \text { Text-to-speech synthesis } & 108\end{array}$

5.8 Articulatory speech synthesis $\quad 111$

$\begin{array}{ll}\text { Problems } & 120\end{array}$

6 Speech Coding $\quad 122$

6.1 Sub-band coding 123

6.2 Transform coding $\quad 125$

6.3 Channel Vocoder 127

6.4 Formant vocoder $\quad 129$

6.5 Cepstral vocoder 130

6.6 Linear predictive vocoders $\quad 130$

6.6.1 The LPC-10 algorithm 132

6.6.2 Multi-pulse and RELP vocoders 134

$\begin{array}{ll}6.7 \text { Vector quantiser coders } & 136\end{array}$

7 Automatic Speech Recognition 138

7.1 Problems in ASR 138

7.2 Dynamic time-warping (DTW) 140

7.2.1 Isolated word recognition 141

7.2.2 Pattern matching 141

7.2.3 Speaker-independent recognition 146

7.2.4 Pattern classification (decision rule) 147

7.2.5 Connected-word recognition 147 


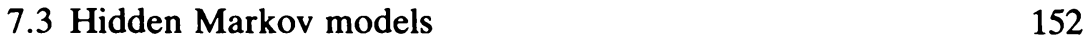

7.3.1 Word recognition using HMMs 155

7.3.2 Training hidden Markov models $\quad 162$

$\begin{array}{ll}7.4 \text { Speaker identification/verification } & 163\end{array}$

$\begin{array}{ll}7.5 \text { Future trends } & 166\end{array}$

$\begin{array}{ll}\text { 7.5.1 Front-end processing } & 167\end{array}$

$\begin{array}{ll}\text { 7.5.2 Hidden Markov models } & 168\end{array}$

$\begin{array}{ll}\text { 7.5.3 Neural networks } & 169\end{array}$

7.5.4 Speech understanding $\quad 171$

$\begin{array}{ll}\text { Problem } & 172\end{array}$

$\begin{array}{lr}\text { References } & 174\end{array}$

$\begin{array}{lr}\text { Index } & 176\end{array}$ 


\section{Series Editor's Foreword}

The rapid development of electronics and its engineering applications ensures that new topics are always competing for a place in university and polytechnic courses. But it is often difficult for lecturers to find suitable books for recommendation to students, particularly when a topic is covered by a short lecture module, or as an 'option'.

Macmillan New Electronics offers introductions to advanced topics. The level is generally that of second and subsequent years of undergraduate courses in electronic and electrical engineering, computer science and physics. Some of the authors will paint with a broad brush; others will concentrate on a narrower topic, and cover it in greater detail. But in all cases the titles in the Series will provide a sound basis for further reading in the specialist literature, and an up-to-date appreciation of practical applications and likely trends.

The level, scope and approach of the Series should also appeal to practising engineers and scientists encountering an area of electronics for the first time, or needing a rapid and authoritative update.

Paul A. Lynn 


\section{Preface}

The relatively new area of speech processing has undergone significant advances in the three decades that have passed since the advent of digital computing in the early 1960s. The last few years have witnessed the transfer of speech technology from the research laboratory to the marketplace. A variety of commercial speech products is now available for speech synthesis, speech recognition and speech coding. This has been made possible by developments in techniques for speech processing, coupled with the significant advances in microprocessor and digital signal processing (d.s.p.) technology.

The aim of this book is to provide an introduction to the techniques and algorithms used in the design of speech systems. The target readership is students studying speech processing in final year undergraduate and postgraduate degree courses in Electrical and Electronic Engineering, Physics and Computing Science. It is hoped that the book will also be of use to anyone beginning to work or carry out research in speech technology. Readers outside these disciplines may find it suitable for general interest reading.

Speech signal processing depends on certain mathematical, systems and communications principles which have to be understood for a proper appreciation of the area. In writing this book, I have tried to minimise, simplify and illustrate the mathematical content. Speech technology is a multi-disciplinary topic, requiring a knowledge of such diverse areas as signal processing, electronics, computing science, linguistics and physiology. While most of these areas are referred to and briefly described in this book, the emphasis is very firmly on the signal processing aspects of speech technology, reflecting the title and my own personal interests. I regret any imbalance that this may cause, but in a short introductory book, it is impossible to cover everything. When writing, I was constantly aware of having to condense important topics or indeed omit them altogether, because of limited space. I hope that this will not detract too much from the value of the book.

The origin of part of this book is courses of lectures, which I have been giving in final year undergraduate and postgraduate courses in Electrical and Electronic Engineering and Computing Science at the University of Ulster in recent years. During that time, I have received a lot of valuable student feedback which I gratefully acknowledge and which has influenced 
my treatment of certain topics. I would like to express my gratitude to Bob Linggard who introduced me to the field of speech processing and who has given me valuable support and encouragement. I am indebted to a number of colleagues, postgraduate and undergraduate students, whose research and project work has made a significant contribution to my understanding of speech signal processing; in particular, I would like to thank David Irvine, Sean Murphy, Neville Ramsey, George Wright, Peter Donnelly, Gary Shannon and Kieran Cooney who also generated some of the diagrams. I should like to acknowledge also the authors of numerous research papers and articles, which I have studied and which have provided me with invaluable insight into the challenging area of speech processing. Unfortunately, in an introductory book of this type, I cannot cite all of them individually.

Finally, I would especially like to thank my wife, Mary, for her constant support and encouragement and who, with one finger, typed the entire manuscript from my illegible scrawl.

F.J. Owens 